\title{
PABLO NERUDA Y LOS MISTERIOS DE LA NATURALEZA
}

\author{
PABLO NERUDA AND THE MYSTERIES OF NATURE
}

\section{PEDRO GUTIÉRREZ REVUELTA ${ }^{1}$}

\section{RESUMEN}

A pesar de haber entrado al mundo literario en esos años locos dominados por la vanguardia, Neruda nunca fue un escritor vanguardista (ni surrealista, ni ultraísta, etc.) ni le atrajeron mucho esas cosas de los manifiestos artísticos en los que la vanguardia fuera tan prolífica. Tampoco creyó en eso del poeta como un pequeño dios. La poesía no reside en la cabeza sino que sube por los pies absorbiendo las fuerzas misteriosas de la naturaleza (algo muy parecido le pasaba a Lorca); fuerzas que el poeta debe transcribir y transformar en poesía. A pesar de que en esos años la moda venía de París (entonces sinécdoque de Europa), Neruda nunca fue ni europeizante ni europeizado. Estas páginas son una indagación en el fundamento literario nerudiano, cuya esencia no se basa en un ejercicio cerebral e ingenioso literario sino en la profunda densidad de lo autóctono americano. La americanidad, como afirmara Gabriela Mistral de la obra de Neruda.

Palabras clave: Huidobro, vanguardia, naturaleza, Puerto Saavedra, Sabat Ercasty, capa maldita, Eva americana, americanidad, Saurio Sagrado.

\section{ABSTRACT}

In spite of having entered the literary world in those crazy years dominated by the vanguard, Neruda was never a vanguard writer (not surrealist, not ultraist, etc.) nor was he much attracted to those artistic manifiestos in which the vanguard was so prolific. He also did not believe in the poet as a lesser god. Poetry does not reside in the head, it rises from the feet while absorbing mysterious forces of nature (something similar occurred to Lorca); forces that the poet had to transcribe and transform into poetry. In

${ }^{1}$ Profesor y Undergraduate Director Department of Hispanic Studies University of Houston, Texas, USA. Doctor en Filosofía y Letras. E-mail: “revuelta@uh.edu” 
spite of the fact that in those years fashion came from Paris (synecdoch for Europe), Neruda was never Europeanizing or Europeanized. These pages are a research into the fundaments of the literary Neruda whose essence is not based on a cerebral exercise or a clever literary device but rather in the profound density of autochthonous America. The americanidad as Gabriela Mistral.

Keywords: Huidobro, vanguard, nature, Puerto Saavedra, Sabat Ercasty, damned cape, American Eve, Americaneity, Saurio Sagrado.

Recibido: 02.04.11. Aceptado: 05.07.12.

Produzca la tierra vegetación: hierbas que den semillas y árboles que den fruto [...] Día tercero.

Génesis 1.11-13

Neruda es, por excelencia, el poeta del Tercer Día de la Creación.

Gabriel Celaya (1972)

\section{EL POETA NO ES UN PEQUEÑO DIOS}

$\mathrm{P}$ ablo Neruda entra en el MUNDo literario de occidente cuando la literatura estaba dominada por la vanguardia europea. Neruda era consciente de la dependencia cultural que la metrópoli impone a la colonia: "la vida cultural de nuestros países en los años 20 dependía exclusivamente de Europa. [...] En cada una de nuestras repúblicas actuaba una <élite> cosmopolita y, en cuanto a los escritores de la oligarquía, ellos vivían en París" (1980a: 75).

Neruda nunca fue muy partidario de esas cosas de la literaturidad; del escritor escribiendo simplemente para sí mismo; de la literatura como lugar de privilegio, atalaya desde la cual el artista adquiere una engañosa superioridad frente la vida; del arte por el arte; de la literatura, en definitiva, como juego y su consecuente frivolidad. Actitud tan a la moda en esos "años locos" de la vanguardia. Neruda desde muy joven entiende la literatura como algo muy serio. Tanto es así que le va la vida en ello. Por eso no puede entender las reglas del "juego" literario que arrastran peligrosamente al artista a la frivolidad excéntrica de los despreocupados jugadores. Por mucho que se le haya tildado (y todavía se sigue haciendo) de vanguardista, surrealista, etc., Neruda nunca lo fue. Ni por su imaginería poética ni por su posición frente a la literatura. Neruda nunca fue europeizante ni europeizado. Aunque sabemos que amaba a Baudelaire y a Rimbaud, y adoraba la poesía lírica castellana. La obra de Neruda es una constante búsqueda 
de lo autóctono americano. Sin resabios estetizantes ni actitudes vanguardistas. Para Gabriela Mistral Neruda representa el mestizaje (sangre india y española) que es la esencia de la americanidad. Nos dice Mistral: "Ahora digamos la buena palabra: americanidad. Neruda recuerda constantemente a Whitman mucho más que por su verso de vértebras desmedidas por un resuello largo y un desenfado de hombre americano sin trabas ni atajos". Y matiza Mistral: "La americanidad se resuelve en esta obra en vigor suelto, en audacia dichosa y en ácida fertilidad" 2 . Lo que de fértil tiene el ácido de la frondosa vegetación del sur chileno. Su poesía es como un "un árbol adosado de lianas y musgos" (Mistral, 1936: 278-79) que se alejaba de la poesía vanguardista de esos años.

Ya en 1926, año en el que se debatían numerosos manifiestos y propuestas vanguardistas, el joven Neruda le confesaba a Silva Castro su desacuerdo con la actitud de algunos de los nuevos artistas y poetas: "Ahora, a algunos de ellos, les ha dado por fingir que escriben por pura diversión y que no les cuesta nada escribir. [...] A mí me cuesta escribir; yo creo que el arte es una cosa seria; no tengo vergüenza de decir que soy escritor" (entrevista con Silva Castro). En Claridad (1924), la revista en la que Neruda publicara sus primeros comentarios y (dis)gustos literarios, encontramos un texto en el que Neruda da su opinión sobre la poesía de Huidobro. La titula "Defensa de Vicente Huidobro" (1924: 8) y firmada por Sachka, seudónimo nerudiano de entonces. Está escrita cuando Neruda tenía apenas 20 años. Es decir, a priori de la guerrilla literaria que tuviera posteriormente con el autor del lúdicro Altazor. En esta "defensa" el joven Neruda afirma que los manifiestos literarios del "trepidante traqueteo del Occidente" no le llaman mucho la atención. Comenta: "Creación, creacionismo, estética nueva, todo eso es fórmula, garabatos, ropa usada". La poesía de Huidobro le parece "extrañamente transparente, ingeniosamente ingenua", "fresca sensación infantil", "juego atrevido" (1924: 8).

Cuarenta y cuatro años más tarde (1968), en el aniversario de la muerte de Huidobro, Neruda dedica un texto a la memoria del autor de Altazor titulado "Búsqueda de Vicente Huidobro". Elogia Neruda en este escrito la poesía huidobriana. Pero también señala la actitud un poco soberbia ${ }^{3}$ de desatender el llamado de la naturaleza: "Se propuso -dice Neruda- desoír

\footnotetext{
${ }^{2}$ En un atractivo artículo, "Neruda: El rizoma de Residencia y el Canto", Mario Rodríguez cuestiona diversas aproximaciones críticas que, según el autor, han pretendido aprisionar a Neruda en "territorios políticos, sociales, americanistas, comprometidos y descomprometidos" (2004: 92). Remitimos a este artículo en la sección Referencias.

${ }^{3}$ Aunque Neruda no utilice este adjetivo pensamos que es pertinente el utilizarlo.
}

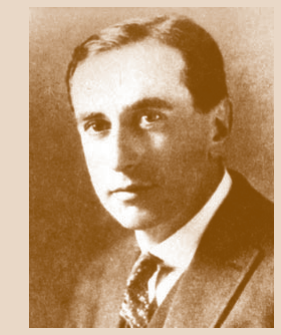

V. Huidobro 


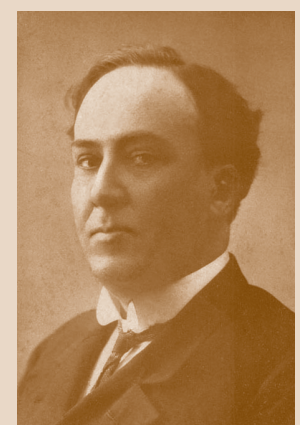

A. Machado la solemnidad de la naturaleza" (1975: 115) ${ }^{4}$. Pensaba Huidobro que el nervio poético residía en la cabeza como explicó en su poética. Su poesía, por lo tanto, se hizo demasiado cerebral, demasiado inteligente. Al desoír los misterios de la naturaleza se había hecho cristalina, conceptual. "Multitud de sus versos -dice Neruda- [...] nacieron tal vez como elaborados por la inteligencia” (1975: 117).

Para Neruda la vida (y el arte) es la permanente relación del hombre con la naturaleza que va determinando su historia. En 1972 vuelve Neruda a insistir sobre el tema. Esta vez en el discurso de aceptación del Premio Nobel: "El poeta no es un pequeño dios", dice Neruda en su discurso (1972: 20). El descubrimiento de lo profundo, misterioso y enigmático en la poesía tiene que hacerlo el poeta no como "un pequeño dios" sino como descubridor y médium de la naturaleza. Le parecía a Neruda que la poesía de Huidobro por haber desatendido las fuerzas de la naturaleza se había convertido en una literatura cerebral. Demasiado inteligente, como dijimos antes; alimentada con la matemática de lo exacto y las numerosas reglas de los manifiestos que proliferaban por esos días. Antonio Machado también expresó su desacuerdo con la nueva moda de la poesía cerebral o conceptual, como la llamaba él, de esos años. Asunto de debate que pone en la misma línea lírica a estos dos grandes poetas. En la "Poética" (1931) que Machado le enviara a Gerardo Diego para su famosa antología Poesía española lo expresa claramente: "Entre tanto se habla [...] de una poesía del intelecto. El intelecto no ha cantado jamás" (Machado, 1989: 1803). Frente a esto proponía Machado una poesía anclada en el tiempo que es "la ley más general de la naturaleza" (1803). Neruda lo sabía muy bien. Huidobro había hecho tanto caso de lo que le decía la cabeza que había desatendido, por ejemplo, lo que dicen los pies y sus zapatos. El contacto con la naturaleza introduce en la poesía los elementos temporales: "Inquietud, angustia, temores, resignación, esperanza, impaciencia" (los nombra Machado, 55). La poesía inteligente pretendía todo lo contrario: eliminar el tiempo. Por medio del pensamiento lógico, que es una actividad destemporalizadora, llegar a la intemporalidad del concepto. La esencialidad que dicta el intelecto eliminaría, para estos poetas, el lastre del tiempo y sus leyes naturales. "Pero al poeta -como dijo Machado y descubre muy temprano Neruda-no le es dado pensar fuera del tiempo" (1803). El poeta necesita descubrir las misteriosas leyes de la naturaleza.

\footnotetext{
${ }^{4}$ Actitud, ahora lo sabemos, que le pasó factura al poeta creacionista. Este breve artículo de Neruda se publicó por primera vez en 1968 en la revista Ercilla pero cito por la edición de 1975.
} 


\section{PUERTO SAAVEDRA: CUNA DEL MUNDO NERUDIANO}

Neruda $-y$ que no se malentiendan como irreverentes estas palabras- no nace de madre ${ }^{5}$. Pablo Neruda nace, como Venus, del mar. Del mar bravo y sonoro del Pacífico sur. El poema de amor número 9, residenciario, es una prueba de ello ${ }^{6}$. Su cuna o su concha -sin connotaciones o con ellas, es igual- está constituida por la desembocadura de un río, de un mar violento y de un "sonido aterrador" (Neruda, 1952b: 3). Pablo Neruda nace en el "Sur del Mundo" (1952b: 3); en el "espacio mítico" (Loyola, 1987: 330) de Puerto Saavedra. "Yo anido en Puerto Saavedra", le confiesa Neruda a González Vera (cito por Rodríguez Monegal, 1966: 46). Nace frente a una costa solitaria y salvaje: "Ruidos inesperados, murmullos de voces desconocidas, cantos avasallados y nuevos cantos vencedores, una música extraña e incontenible se quiebra sobre mi corazón como el viento sobre la selva...", escribe Neruda en febrero de 1923 en Puerto Saavedra (1980b: 164-65). El sonido marino de su océano del "Sur del Mundo", como él mismo lo denomina, permanece para siempre en los oídos del poeta. Más de treinta años después escribe: "Aún en mis oídos [...] oigo la desbocada artillería que me hacía temblar de emoción como si en cada verano de mi infancia hubiera yo cambiado de planeta, y en las puertas erizadas del mar me recibieran las grandes olas de otro mundo, con su sonido aterrador, de creación, de movimiento y fuerza, que escucho todavía" (1952b: 3).

La gran consecución del vasto y "monstruoso" proyecto nerudiano es haber llegado a convertirse en amanuense del océano y transmisor de sus misterios. Una vez consumado este misterioso y anfibio proceso de descifrar el habla del mar, sólo tiene que poner el oído, es decir, el fonendoscopio de sus dedos y auscultar los sonidos de su placenta. Muchos años después lo dirá en sus memorias: "Yo no puedo vivir sino en mi propia tierra; no puedo vivir sin poner los pies, las manos y el oído en ella, sin sentir la circulación de sus aguas y de sus sombras, sin sentir cómo mis raíces buscan en su légamo las substancias maternas" (1980a: 191). La absorción de la energía mineral y vegetal de la naturaleza queda impregnada en el sonido, en el

\footnotetext{
${ }^{5}$ Neftalí Ricardo Reyes, sí; Pablo Neruda, no.

${ }^{6}$ Sobre el tema erótico-onírico de este poema ver el artículo de Loveluck (1975), el de Concha (1985, nota 7) y Loyola (1987, 39-41). Sabemos que el "Poema 9" de amor pertenece al mundo residenciario gracias a la ínclita labor de Hernán Loyola en la búsqueda y captura de la cronotopología nerudiana. En carta a Juan Loveluck le responde a la pregunta que le hiciera éste sobre la fecha de composición del "Poema 9". Loyola respondió que el propio poeta le confirmó que fue escrito en 1932 para la segunda edición de Veinte poemas... Ver Loyola (39) y Loveluck (nota 25).
} 
tentativa d e 1 hombre infinito

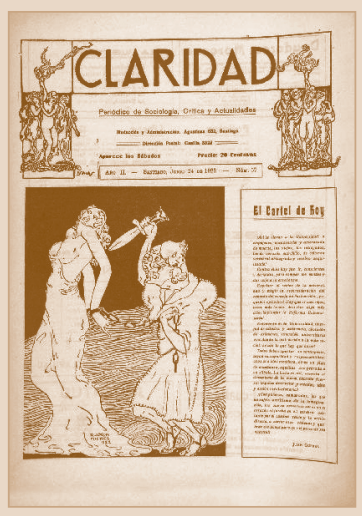

Atenea 507

I Sem. 2013 acto de absorber los sonidos y descifrarlos. Lo decía en Tentativa del hombre infinito: "el cielo era una gota que sonaba [...] pongo el oído y el tiempo como un eucaliptus" (1999: 210). El timón del viaje es primordialmente el oído en el que se impregnan como vegetales y animales marinos los sonidos planetarios y geológicos de la energía oceánica de su planeta originario.

El poeta no puede ser un "pequeño dios" ni debe desatender los sonidos de la naturaleza (como vimos anteriormente). El arte no estaba por encima de ésta. El ingenioso twist vanguardístico, "la naturaleza imita al arte", no era suficiente. Por el contrario, el poeta tenía que auscultar, absorber y transmitir la energía terrestre. Para que Neruda llegara a transcribir el habla oceánica ha tenido que ocurrir un largo proceso de adaptación y aprendizaje en el mundo del hombre. En el largo viaje que representa la obra de Neruda el tiempo planetario se va convirtiendo en un tiempo histórico. El gran saurio sagrado, como lo reconociera Gabriel Celaya (1972: 97), transformó sus branquias. Se adaptó a respirar y a residir en la tierra para integrarse a la historia del hombre.

\section{EL VIAJE NERUDIANO}

Sabemos que el viaje ("no sé por qué siempre mis palabras toman la forma de un viaje", Neruda 1991: 10) ya había empezado en 1923. Muy pronto iban a empezar los poemas de amor. Tenemos la prueba en uno de sus primeras publicaciones (1923) en Claridad. Es una defensa entusiasta que hace Neruda sobre Sabat Ercasty. Destaca del poeta uruguayo las facultades artísticas y los sintagmas significativos que emergen de la energía terrestre. Dice Neruda del poeta uruguayo: "Carlos Sabat es un gran río de fuerzas expresivas [...], es el innumerable coro de las alegrías de los océanos o la desarticulación de todas las preguntas frente al muro fatal [...] y quemándose los dedos moldea figuras en metales ardiendo" (1923b: 4).

La primera geografía nerudiana no es un estado del alma como lo fuera para los románticos, sino una absorción de la energía mineral y vegetal de la tierra que va determinando poco a poco la energía del trabajo humano y su división social. El joven Neruda reconoció en Sabat Ercasty un poder único de reconocimiento y expresión de las fuerzas de la naturaleza: "quién, antes de Sabat...?” (1923b: 4). Por ese camino inicia Neruda su difícil viaje en busca de lo originariamente suyo. En esta misma prosa de Claridad declara el joven Neruda: "Cada poeta cantará lo que quiera, sin hacer caso de preceptos higiénicos. Porque cada uno para cantar debe situarse como Adán: creerse el primer descubridor de las cosas y su primer dueño al entregarles 
nombre" (1923a: 6, subrayado del autor). El primer gran descubrimiento creyó tenerlo el joven Neruda una noche estrellada de Temuco. Fue un momento revelador. Crepusculario iba quedando atrás y "tremendas inquietudes" (Neruda, 1980a: 59) conmovían su poesía. Una noche estrellada de Temuco, nos dice Neruda, "tuve una curiosa experiencia [...] sentí un golpe celeste. Como poseído, corrí a mi mesa, y apenas tenía tiempo de escribir, como si recibiera un dictado. Al día siguiente, leí, lleno de gozo, mi poema nocturno. Es el primero de El hondero entusiasta..." (cito por Sicard, 1981: $33)^{7}$. En sus declaraciones a Cardona Peña comenta Neruda sobre este libro: "Lo escribí a los 18 años [...] Tan conmovido estaba, que escribí íntegro ese poema, quedando agotado y tembloroso, pero con la impresión de algo original en la escritura" (en Cardona Peña, 1955: 25). Creyó el joven Neruda que había encontrado el "verdadero estilo" (Cardona Peña, 1955: 26). Su propia tierra de Adán. Pero el entusiasmo creador dura poco. Por una serie de acontecimientos (que el lector puede encontrar en las referencias dadas) a las pocas semanas le llega una carta de Sabat en la que le confirma la terrible duda que estaba royendo el corazón del joven Neruda: "Pocas veces he leído un poema tan logrado [dice Sabat], tan magnífico, pero tengo que decírselo: sí hay algo de Sabat Ercasty en sus versos" (en Neruda, 1980a: 59). Nos confiesa Neruda cómo la noble carta del admirado poeta uruguayo llegó como un "golpe nocturno" (1980a: 60). Era duro aceptar que el viaje hacia la noche infinita del hondero entusiasta en el que Neruda creía haber encontrado su estilo originario, "esa sumersión de estrellas" y "tempestad austral" (1980a: 60), había sido en vano; ${ }^{8}$ que lo que había creído ser su terreno propio, el que le estaba destinado a sí mismo, no lo era. La noche infinita, en un extraño movimiento cósmico, le había puesto frente al "muro fatal" (1923b: 4). La carta de Sabat, efectivamente, llegó como un "golpe nocturno". Neruda nos cuenta con doloroso detalle cómo la carta de Sabat Ercasty la metió en el bolsillo y la tuvo allí muchos días haciéndola una masa con los dedos" "hasta que se deshizo" (1980a: 60). No era hora de luchar contra las influencias. Había que triturarlas, absorberlas en humus oceánico. Había que virar la nave marina. La dirección no eran las estrellas

Sicard (1981) cita de una conferencia inédita y da otra referencia: "Algunas reflexiones improvisadas sobre mis trabajos". También Neruda ha dejado testimonio de este importante suceso en su poesía en las declaraciones a Cardona Peña (1955) y en sus memorias Confieso que he vivido.

8 “¿Un fracaso poético?", se pregunta Sicard (1981: 41) al hablar de este libro. Para el estudio de este libro, que terminado en 1923 no lo publica Neruda hasta 1933 una vez publicada Residencia 1, remitimos a las páginas de Sicard.

9 “Con mi razón a penas, con mis dedos" dirá años más tarde al iniciar su arriesgado viaje a la madera.
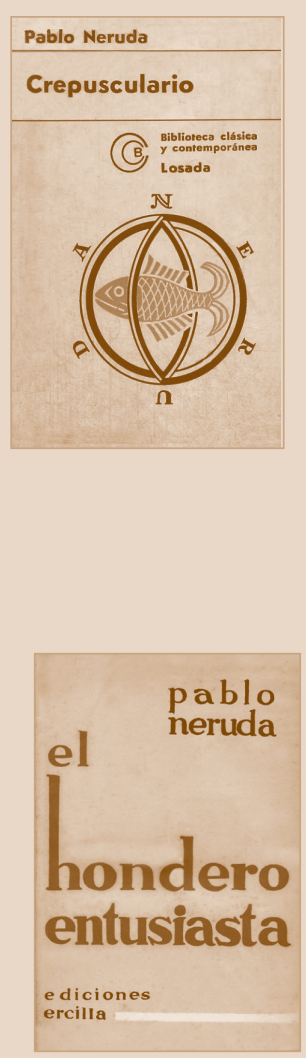

$31 \stackrel{\text { Atenea } 507}{\mid \text { I Sem. } 2013}$ 
(todavía). "Tenía que aprender a ser modesto", "muchas cosas estaban en juego" (Neruda, 1980a: 60). En su fracasado viaje de astronauta -avant la lettre- había aprendido que la dirección no eran las estrellas sino la noche oceánica. Había que descender a las raíces de la tierra por las profundidades abisales donde las estrellas son peces; el peso, ingravidez; el movimiento es casi inmóvil; la caída, ascenso; la ceguera, luz; los dedos, razón... Permanente anfibología del umbral residenciario que nos sumerge siempre, o casi siempre, en el misterio.

Comienza entonces Neruda como respuesta al "fallido" intento de $E l$ hondero sus célebres poemas de amor. Los Veinte poemas de amor son en definitiva una despedida. El 21, la "Canción desesperada", es la bajada a los fondos oceánicos del espeleólogo marino ("buzo ciego", "descubridor perdido"). Para iniciar este viaje (sub)marino frente a las costas de Puerto Saavedra en el océano Pacífico (muelles de Carahue, 1924), Neruda ha tenido antes que desnudarse. Empieza, antes de comenzar su descenso, despojándose de su capa: "como un perro herido rodó a mis pies mi capa" ("Poema 10").

Neruda se queda desnudo frente al mar siguiendo lo dicho en Claridad unos meses antes (mayo de 1923): "cada uno para cantar debe situarse como Adán: creerse el primer descubridor de las cosas y su primer dueño al entregarles nombre" (1923a: 6) ${ }^{10}$. En sus memorias vuelve a insistir: "Yo me lancé a la vida más desnudo que Adán, pero dispuesto a mantener la integridad de mi poesía" (1980a: 300). Este nuevo Adán, frente a la violenta -¡no idílica! ¡ojo!- costa del Pacífico, tiene por necesidad que descubrir a la primera mujer. Por eso la mujer de los Veinte poemas... además de Marisol y Marisombra es la "primera" mujer del continente americano hablando en español. Cortázar, lúcidamente, nos la deja definida así, para siempre, "Eva hablando español":

"En el principio fue la mujer; para nosotros, Eva precedió a Adán en mi Buenos Aires de los años treinta. Éramos muy jóvenes, la poesía nos había llegado bajo el signo imperial del simbolismo y del modernismo, Mallarmé y Rubén Darío, Rimbaud y Rainer María Rilke. [Éramos] Jóvenes pumas ansiosos de morder en lo más hondo de una vida profunda y secreta, de espaldas a nuestras tierras, a nuestras voces, traidores inocentes y apasionados, cerrándose en cónclaves de café y de pensiones

\footnotetext{
${ }^{10}$ El soneto que García Lorca le dedicara a Neruda ("A Pablo Neruda rodeado de fantasmas") lleva el título "Adán". La mágica intuición del andaluz capta en seguida el origen adánico nerudiano.
} 
bohemias: entonces llegó Eva hablando español desde un librito de bolsillo nacido en Chile, Veinte poemas de amor y una canción desesperada. Muy pocos conocían a Pablo Neruda, a ese poeta que bruscamente nos devolvía a lo nuestro, nos arrancaba a la vaga teoría de las amadas y las musas europeas para echarnos en los brazos a una mujer inmediata y tangible, para enseñarnos que un amor de poeta latinoamericano podía darse y escribirse hic et nunc" (Cortázar, 1974: 39).

En Veinte poemas... descubre Neruda su primera geografía y, como tal, su primer tratado cartográfico. Neruda-Adán nació de mar: escamas, caracolas, medusas, caballitos, gelatinas, tinta de calamar... Neruda, él mismo nos lo dice, nació submarino. ¿De qué otra forma podía haber nacido la Eva americana residenciaria? La Eva americana de los 20 poemas (el 21 es otra cosa) nace con los largos femorales de las araucarias de la Araucanía chilena. Nace en el espacio planetario del Sur del Mundo donde al parecer "se escucha una voz de mar enronquecido, una voz metálica y monótona [...] y el cielo parece un océano volcado a las alturas" (Finlayson, 1938: 49).

\section{LOS RUIDOS METÁLICOS DEL TIEMPO}

Veinte poemas... es el instante de la mordedura. Es el comienzo de la cuenta del reloj. Contra el tiempo el único aliado es el amor: "cuerpo de mujer" (comienza el libro). Las fuerzas del viento y del tiempo van a arrastrar a Neruda inevitablemente hasta la costa donde se encuentra la historia. El nacimiento del tiempo es siempre sonoro: ruidos metálicos, voces escondidas, dispersos sonidos que trae el viento soplando las velas del tiempo europeo. A lo largo de los veinte poemas el viento es el causante de las despedidas: sacudiendo "los pañuelos blancos del adiós" ("Poema 4"), o el "viento de la angustia" ("Poema 5"), o el "viento de los sepulcros" acarreando, destrozando, dispersando, desarraigando ("Poema 11"), "matando mariposas" ("Poema 14"), o el viento "zumbando entre los árboles [...] como una lengua llena de guerras y de cantos" ("Poema 4"), más poderoso que el hombre ("Poema 14"), haciendo sonar los pinos con sus hojas de alambre ("Poema 18"). Pinos que se van convirtiendo en picas: tienen hojas de hierro. Surge así entrelazado con el viejo topos amor/guerra, un significado necesario de protección y alianza mutuas. Alianza contra las fuerzas fantasmales del tiempo. Podemos leer en el "Album Terusa" de 1923: "sumergidos en el agua del tiempo [...] ruidos inesperados, murmullos de voces desconocidas, cantos avasallados y nuevos cantos vencedores, una música 


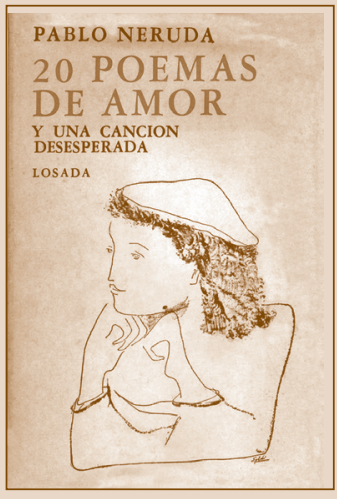

extraña e incontenible se quiebra sobre mi corazón como el viento sobre la selva" (1980b: 164-65).

Los recuerdos sumergidos en los lindes ocultos de la historia avasallan como guerreros extranjeros. Las voces sumergidas y los cantos marciales se cruzan como parte del viento en la selva. Encontramos ya en Veinte poemas el preámbulo que se extenderá a Tentativa y aparecerá más claramente en Residencia: el presentimiento de que la indagación en el tiempo -en la historia de su esencia americana- confluye irremediablemente en un encuentro sangriento ${ }^{11}$.

En Veinte poemas... el amor -cuerpo de mujer- es la única arma contra el tiempo. También en Tentativa... encontramos núcleos de significados que reclaman la aprehensión histórico-geográfica del cuerpo/mapa de la mujer. Es como si dijéramos que la única salvación del amor se encuentra en una fuerza genésica metamorfoseante. El mapa del amor empieza a extenderse en una geografía imprecisa de flora y fauna, de sustratos geológicos y marinos, poblada a su vez por las voces del tiempo. En Veinte poemas hay un instinto material-romántico (no idílico, ¡ojo!, sino más bien anti-idílico) que transmite el amor: la mujer es la tierra ("Poema 1"), la noche ("Poema 2"), una caracola ("Poema 3"), la mañana ("Poema 4"), todo ("Poema 5"), ojos oceánicos ("Poema 7"), abeja blanca ("Poema 8"), un pez ("Poema 9"), pregunta de humo ("Poema 11"), atlas ("Poema 13"), mariposa ("Poema 19"). Para que estas mutaciones se produzcan es imprescindible que las orillas y los perfiles se difuminen en la densidad imprecisa de la noche donde caderas y costas, pechos y colinas, dedos y pájaros se complementen en una fuerza cósmica donde lo telúrico y la noche son los grandes incentivos. Neruda, como gran poeta amoroso que nunca dejó de ser, descubre el tiempo en el amor. Pero el fruto-antídoto contra el tiempo - -joh paradoja!- es el propio tiempo. Surge así al final del libro la congoja frente a lo desconocido: "Quién eres tú, quién eres?” (“Poema 17”).

Estamos en la noche. Estamos frente a las costas de Bajo Imperial (todo remite a Puerto Saavedra, ya lo dijimos) donde empieza la historia. El latigazo del tiempo - "el tiempo latigándome la espalda"- es más fuerte que el amor. Empieza el descenso del gran abandonado, cegado por unas fuerzas obligatorias que le llevan "más allá de todo" ("Canción desesperada"). Este

\footnotetext{
${ }^{11}$ Una de las aportaciones importantes de Jaime Concha (1972) a la lectura de Residencia ha sido el símbolo de la Conquista que el crítico ha estudiado particularmente en "El Sur del Océano" y "El Desenterrado" (Neruda 1904-1936).
} 
explorador ciego, este descubridor perdido, arroja su capa y se queda desnudo frente al mar...

\section{LA CAPA “MALDITA” FERROVIARIA}

Al quitarse la capa queda desnudo frente al mar. Se debería estudiar el acto de vestirse y desvestirse en la obra nerudiana que se complementa, como ya se sabe, con el (re)gusto que tenía Neruda a disfrazarse. Recordemos rápidamente algunos trajes importantes residenciarios: "Con traje nuevo", viene volando Alberto Rojas Giménez; Federico García Lorca viene "vestido de durazno"; Villamediana "Está desnudo". El propio Neruda en Memorial de Isla Negra (1964) nos dice: "Vuelvo a buscar las plumas de mi traje". Este animal sagrado, que dijera Celaya, éste anfíbico saurio -reptil devónicose ha convertido en Quetzalcóatl, la serpiente emplumada (por decir un ejemplo).

Empieza Neruda por desprenderse, era necesario, de su capa modernista. Es un acto de limpieza. De quitar el polvo a ciertas poses aprendidas, a ciertas reminiscencias que ya no consideraba válidas. Debe haber sido difícil, imaginamos, desprenderse de la capa que todo el mundo literario de Santiago conocía. No sólo en los hombros de Neruda sino de otros amigos de la bohemia que se la pedían prestada. Capa por lo tanto no solitaria sino solidaria, más de alianza que de individualismo. Además era una capa que había protegido de la lluvia del sur libros de Baudelaire, de Rimbaud, de Lautremont pero que, en realidad, como bien sabía Neruda y el mundo de la bohemia santiaguina, no era una capa de corte parisino sino de uso ferroviario. Era la capa paterna que la empresa ferroviaria entregara a su padre conductor de tren lastrero. Son estas cosas que pasan en países tercermundistas o en vías de desarrollo como se llaman ahora. La estética está siempre amarrada a una realidad histórica (dependiente). La textura y el corte de confección de la capa ferroviaria no podía competir con las capas made in París. A Baudelaire, imaginamos, le hubiera causado espanto la burda tela.

Pero cumplió su doble cometido. Neruda sabía que tenía que desprenderse del lastre paternal y literario que le impedía moverse libremente. El "perro herido [la capa]" ("Poema 10"), lo estaba de muerte. En el "mezzo del camino" ("Poema 10" de los 20) se le cae la capa al joven Neruda. Posiblemente por el peso excesivo de "literaturidad" que su capa y su figura habían ido adquiriendo en la bohemia de Santiago. En este striptease Neruda se quita principalmente el lastre de la capa maldita que había perfumado 


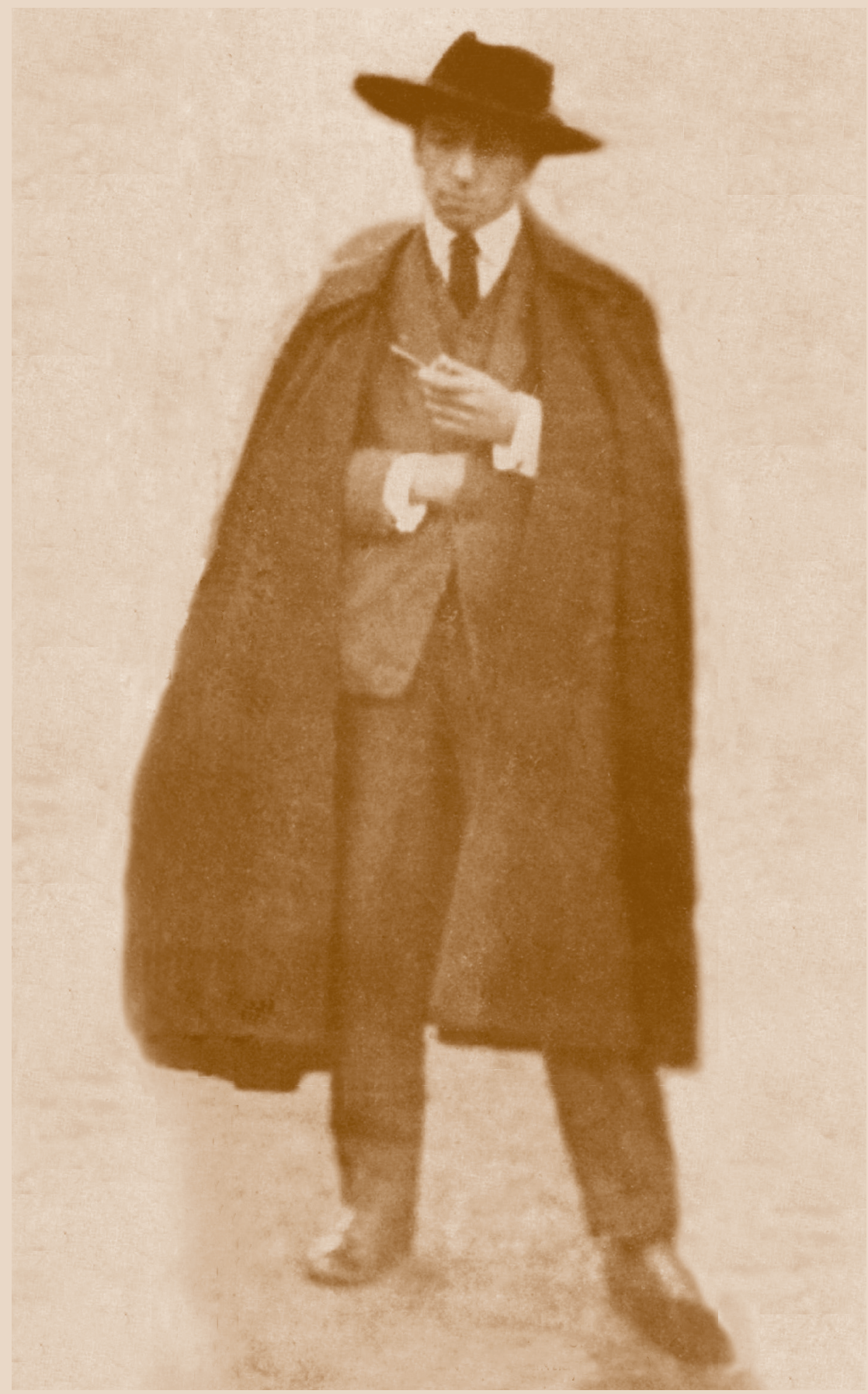

Pablo Neruda en 1924.

\begin{tabular}{l|l} 
Atenea 507 & 36
\end{tabular} 
con aires simbolistas y modernistas los ambientes literarios de Santiago en los primeros años de los veinte. Eliminación de lo maldito ${ }^{12}$. Pero la dependencia que más le preocupaba a Neruda no venía de París (Europa). La influencia realmente preocupante provenía del Cono Sur (América). Nada más terminar de escribir Veinte poemas..., todavía en manuscrito, Neruda hace un "ajuste de cuentas" con Sabat Ercasty. En febrero de 1924, recién terminados de escribir sus poemas de amor, envía una sorpresiva misiva a Sabat Ercasty en un tono que, si no fuera por la admiración que sabemos sentía Neruda por el poeta uruguayo, se podría considerar entre reto y desafío. Le escribe Neruda:

Aquí [Puerto Saavedra: ¿qué otro espacio podría ser?] he recibido su última carta, las once hermosas hojas que después de leídas, tiré sobre el lomo de la alta marea. He terminado aquí [Sur del Mundo] mi nuevo libro Veinte poemas de amor y una canción desesperada que pienso publicar en el mes de Abril. [...] yo durante algún tiempo, pienso que no le escribiré: no debo tocar la parcela de tiempo que Ud. debe entregar a su poderoso esfuerzo, a su doloroso afán, iguales a los míos. También creo que estas cartas son completamente inútiles [...]. En estas cartas se fatiga la mano inútilmente, y como uno tiene otros cauces para entregarse, el corazón hace un juego traicionero con las palabras y las letras. No volveré a escribirle: cambiemos poemas, con todo silencio y tenacidad [...]. Con estas explicaciones, sabrá mi querido amigo Sabat Ercasty, por qué termina aquí esta carta, con este abrazo (en Puccini, 1983: 214).

El viaje tiene que iniciarse solo. Sin dependencias económicas ni literarias. Su "ajuste" literario lo tiene con Ercasty. El ajuste económico con su padre una vez publicado Veinte poemas... Al quitarse la capa no solamente se quita el lastre de la dependencia literaria sino también el lastre de la dependencia paterna: la mesada que le permitía sobrevivir. El joven Neruda, 21 años, le dice a su padre, más o menos, que no quiere ser maestro de francés sino que quiere ser de profesión poeta. Su padre lo echa de casa. Comienza así la dura lucha del artista por la supervivencia. La amistad le salva de la total miseria y le lleva a Ancud donde un amigo gana lo "suficiente" para

\footnotetext{
${ }^{12}$ Sabemos que algunos de sus amigos lo eran. Y como tal murieron: Joaquín Cifuentes Sepúlveda, Alberto Rojas Giménez..., son algunos casos. Esto no impide que Neruda siempre se acuerde del gran "maldito" por antonomasia. Le dice Neruda a Silva Castro en 1926: "Un día voy a escribir unas 30 páginas sobre Rimbaud, cuya figura me interesa mucho”. Bien pudiera ser que las páginas del discurso de aceptación del Premio Nobel (1972) sea el cumplimiento de la promesa hecha a Silva Castro cuarenta y seis años antes.
} 
los dos $^{13}$. Intenta sobrevivir vendiendo estampillas en el mercado. Luego, también en Ancud, entendiendo la literatura como valor de cambio, busca el mercado literario y escribe "a petición de su editor" su ¿"novela"? El habitante y su esperanza (1926). Mercancía que no le saca en absoluto de su miseria. Finalmente su vida profesional empieza (1927) en un consulado de malamuerte como cónsul de tercera en Asia... Allí, por cinco años, escribirá la mayoría de los poemas de la primera Residencia ${ }^{14}$. En España terminará Residencia 2. Al quitarse los lastres -la capa- mencionados, Neruda alcanza un estrato subterráneo tan único y tan profundo que de esta exploración saldrá Residencia en la tierra. Para Cortázar este libro representa el lenguaje y el ver americano. Lo explica así: "Aceptar, asimilar Residencia en la tierra exigía acceder a una dimensión diferente de la lengua y, desde allí, ver americano como jamás se había visto hasta entonces" (39).

Si Residencia en la tierra fue la sima, la zona abisal, fondo del océano con sus gelatinas, algas y moluscos, Alturas de Macchu Picchu es la cima, la madera petrificada. Piedra casi, como la dariana, insensitiva al personalismo disfrazado de la retórica de la elocuencia. Alturas de Macchu Picchu es el viaje a ultratumba, no por el camino de Orfeo y las influencias europeas, sino por el contacto con la naturaleza, por el ascenso de la cultura indígena para rescatar triunfalmente las voces populares de todos los indo-iberoamericanos muertos que representa la ruina de Macchu Picchu. Nunca estuvo Neruda más alto ni más profundo. Y no exageramos.

\section{EL PODER DE LA NATURALEZA}

La naturaleza poseerá en Neruda un grado notable de eficacia.

Jaime Cocha $(1971,16)$

Si hemos empezado estas páginas presentando la opinión que Neruda tuviera de la poesía de Huidobro no ha sido con afán de levantar viejas rencillas literarias. Grandes poetas fueron los dos. Hemos querido simplemente señalar que Neruda está en desacuerdo con la poesía del intelecto, los juegos vanguardistas, las escuelas literarias, etc., sobre todo porque esta actitud avant-garde conlleva un alejamiento de la naturaleza.

\footnotetext{
${ }^{13}$ Su amigo Rubén Azócar, que sí había terminado sus estudios de maestro, fue destinado a Ancud y le ofrece a Neruda su ayuda amigable y monetaria.

${ }_{14}$ Para comprobar las fechas de composición de los poemas de Residencia ver la excelente edición de Loyola (1987).
} 
Todas las alabanzas y elogios que Neruda hiciera de numerosos artistas y escritores están fundamentados en el poder que tiene el arte cuando entra en conexión con las fuerzas genésicas de la naturaleza tanto geológicas como marinas. Son constantes las referencias minerales / vegetales / marinas que Neruda considera necesario resaltar en sus alabanzas de las obras que para él son ejemplos de excelencia artística. Veamos algunos de ellos:

Para Neruda la obra del escultor Alberto ${ }^{15}$ es una "transfigurada geología" y en su alabanza hace una defensa del artista como descubridor. De "descubrimiento acerbo", de "atrevida exploración" clasifica Neruda la obra de Alberto. Porque el descubridor no es otra cosa que un explorador afortunado. Alberto, para Neruda, es el médium de la tierra: "La tierra marca sus trabajos [...], el mismo planeta a través suyo ha penetrado sus trabajos, dándoles para siempre tejido y temblor de grandeza terrestre". En definitiva la obra de Alberto es una "exploración dionisíaca del mundo ibérico" (Neruda, 1936). Gran defensa del artista en contacto con la tierra.

No muy diferente a la obra de Alberto es para Neruda el viaje "subterráneo, como una veta de profundo metal endurecido" (1945: 5) que determina la poesía de Gabriela Mistral. En noviembre de 1945, frente al Senado de la República, lee Neruda el homenaje a Gabriela Mistral por habérsele concedido el Premio Nobel de Literatura. En la poesía de Mistral se arraiga, para Neruda, el cobre de Chuquicamata y el carbón de la tierra de Coronel. Gabriela Mistral está en contra de "un falso concepto aristocrático y europeizante" de la literatura y el arte. "Ella misma es [nos dice Neruda] parte de nuestra geografía, lenta y terrestre, generosa y secreta" (1945: 5). Así como la tierra ("el mismo planeta", 1936) había marcado el arte en la faz de Alberto dejándole profundas arrugas, la "alta y hermosa cabeza araucoespañola de Gabriela Mistral" está forjada en la "veta de profundo metal endurecido" que es su obra. "Ella misma -dice Neruda- es como una parte de nuestra geografía” (1945: 5). La persona de Mistral representa el territorio chileno en su geografía exterior y en su íntima geología. Mistral no desoyó los sonidos de la naturaleza. Literatura y Arte, sí; Naturaleza, también.

Su homenaje al poeta Ángel Cruchaga Santamaría al ser nombrado presidente de la Alianza de Intelectuales de Chile para Defensa de la Cultura

\footnotetext{
${ }^{15}$ Alberto Sánchez (1895-1964). Escultor toledano. En junio de 2001 se inauguró, a la entrada del Museo Reina Sofía, una réplica de su escultura El pueblo español tiene un camino que conduce a una estrella que formó parte de la Exposición Internacional de París en 1937, en la que también se encontraba el famoso Guernica de Picasso. La recuperación de Alberto en España data de 1970 con una exposición en la Biblioteca Nacional. Ya en 1936 destacaba Neruda el poder evocativo del arte de Alberto que era un asiduo participante en las reuniones en la Casa de las Flores de Neruda.
} 
(julio de 1946), es un parecido viaje de espeleólogo. Dice Neruda del poeta chileno: "Nada más sideral y floral que su eminente poesía, nada más enterrado, como la secreta primavera del cuarzo" (1946: 1). Lo mismo que Alberto y Mistral, Cruchaga es una parte de "nuestra geología". De nuevo la tierra se apodera de estos poderosos médiums descubridores.

Semejante su alabanza a Nazim Hikmet: la "política poesía de nuestro tiempo [...] tiene músculos de minero, y tiene tierra y metal de las minas profundas" (1952a: 1). O de Siqueiros: "esta fuerza dinámica de Siqueiros, esta especie de conmoción cosmogónica, este gran volcán de la pintura, es difícil pensarlo, soñarlo dentro de una cárcel” (1961: II-III). También en las páginas preliminares al bello libro Andina de Roberto Magni, Neruda nos explica el complejo y difícil proceso que han tenido que hacer los artistas americanos para descubrir, capturar y renombrar una tierra conquistada: "Nosotros los americanos [...] hemos tenido que excavar, para buscar debajo de las cenizas imperiales las gemas deslumbradoras y los colosales fragmentos de los dioses perdidos [...] hemos tenido que mirar a las alturas: a veces una torre de los antiguos tiempos" (1991: 6; el texto de Neruda está firmado en Condé-sur-Iton, Francia, enero de 1972). Sin duda Machu Picchu una de ellas. Neruda admira a los artistas que, para liberar con su arte una tierra conquistada, tuvieron que emprender un difícil y arriesgado viaje a la geología terrestre. Al final de su vida, en la bellísima introducción al libro Andina, nos confiesa Neruda: "No sé por qué mis palabras asumen siempre la forma de un viaje" (1991: 10). Es más, se podría afirmar que el viaje de Neruda fue un proceso de complicada metamorfosis.

\section{LA METAMORFOSIS NERUDIANA: EL GRAN SAURIO SAGRADO}

Neruda es, por excelencia, el poeta del Tercer Día de la Creación: el gran saurio sagrado.

Gabriel Celaya (1972)

Así como la antropología estudia la evolución corporal y cultural (mental) del hombre como ser social, se debería hacer un estudio de la metamorfosis corporal nerudiana que acompaña a los diferentes estadios de su obra. La supuesta metamorfosis nerudiana es fácil de demostrar. Sólo hay que recoger las numerosas referencias y testimonios que a este respecto han hecho críticos, novelistas y poetas que lo conocieron para que se haga evidente este singular proceso nerudiano. Todas ellas son coincidentes en que Neruda es un ser antediluviano, anterior a la creación del hombre, originario 
del período terciario, como una especie de animal sagrado, de raíz vegetal y primitiva materia marina, ctenóforo, selacio, anfibio que saliendo del mar termina finalmente adaptándose, no sin lento y paciente proceso, a una existencia entre los hombres. Para todos ellos Neruda es un ser salido del mar. Veamos algunas de estas "extravagantes" y "provocadoras" indagaciones en la esencia nerudiana.

Empecemos por la visión emotiva y lúcida de Gabriel Celaya. No nos presenta un retrato exacto, como él mismo nos dice, sino una imagen simbólica de la poderosa personalidad del poeta chileno. Neruda tiene "branquias anteriores a la aventura humana con el Ouroboros o el pez-hombre Oanes de nuestros orígenes". Para Celaya Neruda es el Gran Saurio Sagrado: "Neruda es, por excelencia, el poeta de ese Tercer Día de la Creación: el gran saurio sagrado, como antes decía, [...] hipnótico, [...] dragón del Terciario" (97). Ramón Gómez de la Serna también ratifica el origen marino que proyecta el cuerpo que contempla: "como si anduviésemos sobre un inmenso monstruo del que no vemos la cabeza ni la cola" (1961: 812). Cortázar por su parte destaca el origen selacio de Neruda: "Su lenta mirada de tiburón varado" (1974: 39) ${ }^{16}$. Cortázar captura esta mirada de ser antediluviano para precisar que América Latina no es un satélite del tiempo histórico europeo sino que tiene su propia (pre)historia. La mirada de Neruda, por ejemplo, es un caso concreto. Es la herencia milenaria del continente americano. María Zambrano había querido hacérselo ver así al mundo de Occidente, quizá sin mucho éxito: "La poesía de Pablo Neruda nos planta en medio de un orbe desconocido para un hombre de esta tradición occidental. [...] se trata de una cultura otra, y no decimos nueva porque no creemos que lo sea, sino al revés: antigua, antiquísima" (1938: 36).

Este saurio sagrado, como dijera Celaya, descubre la herencia americana absorbiendo las grandes fuerzas de la naturaleza geológica y marina. El joven Neruda (Asia, 1930) le confiesa a Eandi en una carta el descubrimiento de su nuevo "método" poético: "una absorción física del mundo" (Aguirre 1980: 46).

Este complejo y paciente proceso de absorción es imposible que se hubiera producido en un encuentro de imágenes inteligentes y escritura automática. Se realiza en una lenta y difícil inmersión por medio de "la aus-

\footnotetext{
${ }^{16}$ Hay otras "radiografías" nerudianas que queremos indicar brevemente. Jorge Edwards, en su libro Adiós, poeta (1990), amalgama las referencias de Celaya (1972) y Cortázar (1974): “ojillos de saurio, de lagarto prehistórico” (44). Simone Tery (1943), refiriéndose a la esencia tardígrada nerudiana, había dicho de Neruda: "elefante niño [...] con ademanes lentos, perezosos". También el artículo de Caballero Bonald (1971) y el de Lavín Cerda (1984).
} 
cultación de la energía material del mundo" (Concha 1985: 116). Rojas Paz también lo entendió así: "cada gran poeta es como un explorador que se interna en regiones desconocidas de la sensibilidad humana" (1937: 122). Toda gran obra de arte se ha fraguado en el plancton y en el magma. En el constante contacto con la naturaleza donde el poeta chileno encontró la mayor y mejor fuente de su fundamento poético.

\section{CODA FINAL}

Fértil simiente de la continuidad nerudiana. Para ello tuvo antes, como él mismo nos dice, que precipitarse "al fondo oscuro de nuestros ríos de salitre y azufre" (1938: 11). Le fue imprescindible la energía del planeta para poder realizar el otro viaje a la comunidad del hombre y su historia.

\section{REFERENCIAS}

Aguirre, M. (1980). Pablo Neruda - Héctor Eandi. Correspondencia durante "Residencia en la tierra". Buenos Aires: Editorial Sudamericana.

Cardona Peña, A. (1955). Pablo Neruda y otros ensayos. México D. F.: Ediciones Andrea.

Celaya, G. (1972). “Pablo Neruda. Poeta del Tercer Día de la Creación”. Revista de Occidente 36, 95-101.

Caballero Bonald, J. M. (1971). "Neruda o la táctica del taumaturgo". Cuadernos para el diálogo 98 (nov.), 37-39.

Concha, J. (1971). "Neruda: naturaleza y poesía”. El Siglo (Revista Semanal), 31 Oct. (s. p.).

(1972). Neruda (1904-1936). Santiago de Chile: Universitaria. (1985). “Cruzar' en Residencia en la tierra”. Revista de Crítica Literaria Latinoamericana 21-22, 109-119.

Cortázar, J. (1974). “Neruda entre nosotros”. Plural (mar.), 38-42.

Edwards, J. (1990). Adiós, poeta. Barcelona: Tusquets.

Finlayson, C. (1938). “Paisaje en Pablo Neruda”. Atenea 160 (oct.), 49-60.

García Lorca, F. (1965). Obras completas. Madrid: Aguilar.

Gómez de la Serna, R. (1961). Retratos completos. Madrid: Aguilar.

Lavín Cerda, H. (1984). "Pablo Neruda o la cornucopia del animal oscuro". Cuadernos Americanos 252. 1, 11-128.

Loveluck, J. (1975). "El navío de eros: Veinte poemas de amor..., número nueve”. Isaac Jack Lévy y Juan Loveluck (Eds.), Simposio Neruda (pp. 217-231). South Carolina: University of South Carolina Press.

(1983). "Una carta desconocida de Pablo Neruda". Hispania 66 (sept.), $420-22$. 
Loyola, H. (1987). “Introducción“, “Apéndice I” y “Apéndice II”. Residencia en la tierra de Pablo Neruda. Ed. Hernán Loyola. Madrid: Cátedra.

(1999). "Neruda moderno / Neruda posmoderno". América sin nombre 1 (dic.), 21-32.

Machado, A. (1989). Prosas completas. Tomo 2. Ed. Oreste Macrí. Madrid: Espasa-Calpe.

Mistral, G. (1936). "Recado sobre Pablo Neruda”. Repertorio Americano, 23 abril, 278-279.

Neruda, P.[firmado Sachka] (1923a). "Libros". Claridad 4.86 (5 mayo): 6. Incluido en Obras Completas IV de Pablo Neruda [OCPN IV]. Ed. Hernán Loyola. Barcelona: Galaxia Gutenberg / Círculo de Lectores: 310.

[firmado Sachka] (1923b). "Los libros". Claridad año 4.87 (12 mayo): 4. Incluido en $O C P N I V$, p. 311.

[firmado Sachka] (1924). "Defensa de Vicente Huidobro". Claridad 5.122 (jun.): 8. Incluido en OCPN IV, p. 322.

(1936). "Escultor Alberto". Repertorio Americano (5 sept.). Incluido en OCPN IV, pp. 385-386.

(1938). "La educación será nuestra epopeya". Aurora de Chile (Santiago)

6 (3 dic.): 11, 12, 14. Incluido en OCPN IV, p. 408.

(1939a). "Homenaje a Antonio Machado". Frente popular (Santiago) (16 mar.), p. 2.

(1939b). "Homenaje a Machado en Buenos Aires". Aurora de Chile (Santiago) 10 (6 mayo), p. 5.

(1945). “Homenaje a Gabriela Mistral”, en El Siglo 21 nov., p. 5.

(1946). "Ángel Cruchaga Santa María: Poeta y combatiente por la defensa de la cultura”, en El Siglo 14 jul., p. 1.

(1952a). "Mi hermano Nazim". Pro Arte (26 mar.), p. 1.

(1952b). "Muertos de América". Democracia (26 jun.), p. 3. Incluido en OCPN IV: 825.

(1961). "No es el pueblo el que lo encarcela”. Política (México), 17 (1 enero), pp. II-III. 29.

(1968). “Búsqueda de Vicente Huidobro”. Ercilla 1703 (7 de febrero), p.

(1972). Discurso pronunciado con ocasión de la entrega del Premio Nobel de Literatura (1971). París: Centre de Recherches Hispaniques.

(1975). “Búsqueda de Vicente Huidobro (1968)”. En Vicente Huidobro y el creacionismo. Ed. René de Costa. Madrid: Taurus, pp. 115-116.

(1980a). Confieso que he vivido. Barcelona: Argos Vergara.

(1980b). El río invisible. Poesía y prosa de juventud. Barcelona: Seix Barral. (1987). Residencia en la tierra. Ed. Hernán Loyola. Madrid: Cátedra.

(1991). "Presentación”. En Roberto Magni y Enrique Guidon, Andina (pp. 6-10). Madrid, Grupo Libro 88, 2a ed.

(1999). Obras completas I. Ed. Hernán Loyola. Barcelona: Galaxia Gutenberg / Círculo de Lectores. 
(2001). Obras completas IV. Nerudiana dispersa I (1915-1964) [OCPN $I V]$. Ed. Hernán Loyola. Barcelona: Galaxia Gutenberg / Círculo de Lectores.

Puccini, D. (1983). “Cuatro cartas de Neruda a Sabat Ercasty”. Escritura 8.16 (jul.-dic.), 207-216.

Rodríguez, M. (2004). "Neruda: El rizoma de Residencia y el Canto". Atenea 489, 89-105.

Rodríguez Monegal, E. (1966). El viajero inmóvil. Introducción a Pablo Neruda. Buenos Aires: Losada.

Rojas Paz, P. (1937). “Pablo Neruda. La poesía y su inseguridad”. Nosotros 2.19 (oct.), 121-134.

Sicard, A. (1981). El pensamiento poético de Pablo Neruda. Madrid: Gredos.

Silva Castro, R. (1926). "Una hora de charla con Pablo Neruda”. El Mercurio 10 oct.

Tery, S. (1943). "Neruda”. El Siglo 12 sept.

Zambrano, M. (1938). "Pablo Neruda o el amor de la materia", en Hora de España 23 (nov.), pp. 35-42. 